\title{
PENGGUNAAN INTERPOLASI HERMITE KUBIK DALAM PENYELESAIAN PERSAMAAN STURM-LIOUVILLE DENGAN METODE ELEMEN HINGGA
}

\section{Dwi Maryono \\ Program Studi Pendidikan Matematika FKIP UNS}

\begin{abstract}
ABSTRAK
Penerapan matematika dalam bidang fisika sering menghasilkan suatu masalah nilai eigen, khususnya persamaan Sturm-Liouville. Dari persamaan ini dapat dibentuk syarat batas Dirichlet atau campuran yang homogen. Untuk mendapatkan penyelesaian pendekatan nontrivial dapat digunakan metode elemen hingga. Tujuan dari penulisan ini adalah menentukan penyelesaian pendekatan (nilai eigen dan fungsi eigen pendekatan) dari persamaan Sturm-Liouville dengan metode elemen hingga khususnya, dengan interpolasi Hermite kubik. Hasil secara numerik menunjukkan bahwa metode tersebut cukup baik untuk menyelesaikan persamaan Sturm Liouville, di mana error yang dihasilkan sangat tergantung pada panjang elemen yang diambil dan juga tergantung pada indeks nilai/fungsi eigennya.

Kata kunci : elemen hingga, Sturm-Liouville, Hermite kubik, nilai eigen
\end{abstract}

\begin{abstract}
Eigenvalue problems especially Sturm-Liouville equations often occur in physics. Homogenous Dirichlet or mixed boundary value problems can be constructed from these equations. The nontrivial solution from these equations can be obtained using finite element methods. The purpose of this research is to obtain the details of the construction of finite element method using cubic Hermite interpolation in solving Sturm-Liouville equations. The result shows that the solutions of the finite element method using cubic Hermite interpolation is good enough in solving Sturm Liouville equation. Based on the example, its error depends on the element's length and the index of the eigenvalue or eigen function.
\end{abstract}

\section{PENDAHULUAN}

Penerapan matematika dalam bidang fisika sering menghasilkan suatu bentuk khusus dari masalah syarat batas yang dikenal dengan masalah nilai eigen. Masalah syarat batas seperti ini pada umumnya berbentuk persamaan Sturm-Liouville, seperti persamaan berikut.

$-\frac{d}{d x}\left(p(x) \frac{d u}{d x}\right)+q(x) u=\lambda u, \quad 0<x<L$,

dengan $p^{\prime}(x), p(x)>0, q(x)$, dan $w(x)>0$ adalah fungsi yang kontinu pada domain $\Omega=(0, L)$ dan $\lambda \in \mathfrak{R}$ adalah suatu parameter.

Dari persamaan (1) dapat dibentuk syarat batas

1. Dirichlet : $u(0)=u(L)=0$,

2. Campuran: $u(0)=u^{\prime}(L)=0$ $u^{\prime}(0)=u(L)=0$.
Persamaan (1) dengan syarat batas (2a) dan (2b) mempunyai penyelesaian $u=0$ (penyelesaian trivial). Persamaan mempunyai penyelesaian nontrivial jika dan hanya jika parameter $\lambda$ berharga tertentu yang disebut dengan nilai eigen. Penyelesaian $u$ yang terkait dengan eigen $\lambda$ disebut fungsi eigen. Penyelesaian (1) dapat diperoleh dengan metode beda hingga (Gerald dan Wheatley, 1994) dan metode elemen hingga (Reddy, 1984). Metode beda hingga lebih sederhana dibandingkan dengan metode elemen hingga tapi fungsi eigen pendekatan yang diperoleh tidak berbentuk fungsi tapi hanya nilai-nilai pendekatan dari fungsi eigen eksak di titik-titik yang ditentukan sehingga untuk mendapatkan nilai pendekatan di titik lain diperlukan perhitungan lagi dari awal. Sedangkan dengan metode elemen hingga, hasilnya berupa fungsi, 
yang diperoleh dari interpolasi terhadap nilainilai pasangan di antara domainnya.

Dalam metode elemen hingga, fungsi pendekatan diperoleh dari polinomial interpolasi, biasanya menggunakan interpolasi Lagrange. Hasil dari metode elemen hingga dengan menggunakan interpolasi Lagrange akan menghasilkan fungsi pendekatan yang merupakan keluarga dari kelas himpunan $C^{0}(\Omega)$ dengan

$C^{m}(\Omega)=\left\{u(x), x \in \Omega / u, u^{\prime}, \ldots, u^{(m)}\right.$ kontinu pada $\left.\Omega\right\}$

Menurut Carey dan Oden [1983], untuk kasus dengan orde yang lebih tinggi atau dengan menggunakan metode variasional seperti kolokasi diperlukan fungsi penyelesaian pendekatan yang merupakan keluarga dari kelas himpunan yang lebih tinggi dari $C^{0}(\Omega)$. Interpolasi tersebut adalah interpolasi Hermite kubik. Untuk itu penulis mencoba mengaplikasikannya dalam menentukan penyelesaian pendekatan persamaan Sturm-Liouville dengan metode elemen hingga.

\section{PEMBAHASAN}

\section{Formulasi Variasional dan Pendekatan Galerkin}

Secara umum persamaan diferensial dapat dinyatakan dengan

$$
A u=f \text { pada } \Omega
$$

dengan $A$ adalah operator linear atau nonlinear dari suatu ruang hasilkali dalam $U$ ke suatu ruang hasilkali dalam $V$ dan $\Omega$ domain dari persamaan diferensial (Reddy, 1984). Jika $A$ adalah operator linear simetris dan definit positif pada ruang Hilbert $H$ maka dapat dibentuk fungsional kuadratik

$$
I(v)=\langle A v, v\rangle_{H}-2\langle f, v\rangle_{H} .
$$

dengan $\langle$,$\rangle adalah hasil kali dalam. Jika fungsi$ $u$ adalah penyelesaian dari (3) maka menurut Reddy [1986], $u$ akan meminimumkan $I(v)$. Menurut Strang dan Fix [1973], jika $u$ adalah minimum dari $I(v)$ maka $u$ memenuhi $\langle A u, v\rangle_{H}=\langle f, v\rangle_{H}$ untuk setiap $v \in H$

Persamaan (4) disebut sebagai formulasi variasional dari persamaan (3). Fungsi $u$ dalam (4) disebut fungsi trial dan fungsi $v$ disebut fungsi tes. Dengan menerapkan (4) terhadap (3) maka domain dari penyelesaian $u$ dapat diperluas menjadi ruang yang lebih besar daripada $H$. Ruang ini disebut ruang admissibel, dinotasikan dengan $H_{A}$. Dengan demikian, formulasi variasionalnya menjadi

$\langle A u, v\rangle_{H}=\langle f, v\rangle_{H}$ untuk setiap $v \in H_{A}$ atau

$B(u, v)=l(v)$ untuk setiap $v \in H_{A}$ dengan $B: H_{A} \times H_{A} \rightarrow \mathfrak{R}$ adalah fungsi bilinear dan $l$ adalah fungsional linear.

Pendekatan Galerkin dari persamaan (3) diperoleh dengan membawa persamaan (5) ke dalam subruang berdimensi hingga $H^{h} \subset H_{A}$ sehingga pendekatan Galerkin $u^{h}$ memenuhi

$$
B\left(u^{h}, v\right)=l(v) \text { untuk setiap } v \in H^{h} \subset H_{A} .
$$

Untuk masalah nilai eigen

$$
A u=\lambda u,
$$

digunakan metode variasional

$$
\langle A u, v\rangle=\lambda\langle u, v\rangle \text { untuk setiap } v \in H_{A}
$$

atau dapat disajikan 


$$
B(u, v)=\lambda\langle u, v\rangle \text { untuk setiap } v \in H_{A}
$$

dengan $B: H_{A} \times H_{A} \rightarrow \mathfrak{R}$ adalah fungsi bilinear dan $H_{A}$ adalah ruang fungsi admissibel.

Pendekatan Galerkin dari persamaan (6) diperoleh dengan membawa persamaan (7) ke dalam subruang berdimensi hingga $H^{h} \subset H_{A}$ sehingga pendekatan Galerkin $u^{h}$ memenuhi

$$
B\left(u^{h}, v\right)=\lambda\left\langle u^{h}, v\right\rangle \text { untuk setiap } v \in H^{h} .
$$

\section{Interpolasi Hermite}

Misalkan diberikan domain $\Omega=\left[x_{i-1}, x_{i}\right]$. Untuk menerapkan interpolasi Hermite, domain $\Omega$ ditransformasikan secara linear ke domain $\hat{\Omega}=[-1,1] \quad$ oleh pemetaan $\xi=\left[2 x-\left(x_{i-1}+x_{i}\right)\right] /\left(x_{i}-x_{i-1}\right)$. Menurut Carey dan Oden [1983], polinomial Hermite kubik mempunyai bentuk

$$
\hat{U}(\xi)=\sum_{j=1}^{2} \hat{u}_{j} \hat{\psi}_{j}^{0}(\xi)+\sum_{j=1}^{2} \hat{u}_{j}{ }^{\prime} \hat{\psi}_{j}^{1}(\xi)
$$

dengan fungsi-fungsi basis adalah

$$
\begin{aligned}
\hat{\psi}_{1}^{0}(\xi) & =(\xi-1)(\xi+2) / 4, \\
\hat{\psi}_{1}^{1}(\xi) & =(\xi-1)(\xi+1) / 4, \\
\hat{\psi}_{2}^{0}(\xi) & =(\xi+1)(2-\xi) / 4, \\
\hat{\psi}_{2}^{1}(\xi) & =(\xi+1)(\xi-1) / 4 .
\end{aligned}
$$

Dengan pemetaan $\xi \rightarrow x$ dapat diperoleh basisbasis $\psi_{j}^{0}$, dan $\psi_{j}^{1}$ pada domain $\Omega$ sehingga polinomial Hermite menjadi

$$
U(\xi)=\sum_{j=1}^{2} u_{j} \psi_{j}^{0}(x)+\frac{h}{2} \sum_{j=1}^{2} u_{j}{ }^{\prime} \psi_{j}^{1}(x)
$$

dengan $h=x_{\mathrm{i}}-x_{i-1}$ adalah panjang domain $\Omega$

\section{Metode Elemen Hingga}

Kelemahan dari metode variasional adalah sulitnya mencari fungsi trial $u$ dalam persamaan (4). Penyelesaian pendekatan yang diperoleh dari interpolasi fungsi kurang efektif jika digunakan pada interval yang besar. Berdasarkan hal tersebut, pendekatan Galerkin diharapkan berhasil dengan baik jika domain $\Omega$ dibagi menjadi subdomain-subdomain yang lebih kecil. Teknik seperti ini disebut dengan metode elemen hingga.

Secara garis besar langkah-langkah dasar metode elemen hingga menurut Reddy [1984], Carey dan Oden [1983], dan Gerald dan Wheatley [1994] untuk menyelesaikan masalah syarat batas pada domain $\Omega=(0, L)$ adalah sebagai berikut

1. Pembagian domain $\bar{\Omega}=\Omega \cup \Gamma=[0, L]$, dengan $\Gamma$ batas dari $\Omega$ menjadi subdomain $\bar{\Omega}_{e}, \quad e=1,2, \ldots, E$ yang disebut dengan elemen-elemen hingga sesuai dengan ketentuan yang diberikan Griffin dan Reddy (1988) sebagai berikut.
a) Setiap $\bar{\Omega}_{e}$ tertutup dan tak kosong
b) $\Omega_{e} \cap \Omega_{j}=\phi$, untuk $j \neq e$
c) $\Omega=\bigcup_{e=1}^{E} \bar{\Omega}_{e}$.

2. Mengkonstruksikan fungsi bentuk $\psi_{i}^{e}, i=$ $1,2, \ldots, N_{e}$ untuk tiap $\bar{\Omega}_{e}$ sedemikian sehingga fungsi pendekatan $u^{h}$ dapat ditulis dalam bentuk

$$
u_{e}^{h}(x)=\sum_{j=1}^{N_{e}} \alpha_{j}^{e} \psi_{j}^{e}, e=1,2, \ldots, E .
$$

3. Menerapkan metode variasional dengan fungsi pendekatan yang yang telah 
diperoleh dari langkah 2 sehingga dapat diperoleh sistem persamaan linear untuk masing-masing elemen.

4. Mengkombinasikan sistem persamaan linear yang diperoleh dari tiap elemen.

5. Menerapkan syarat batas yang diberikan dan menyelesaikan sistem persamaan akhirnya.

\section{Formulasi Variasional untuk Persamaan}

\section{Sturm-Liouville}

Pandang persamaan Sturm-Liouville

$$
A u=-\frac{d}{d x}\left(p(x) \frac{d u}{d x}\right)+q(x) u=\lambda u, \quad 0<x<L
$$

dengan syarat batas (2a) dan (2b) dan $p^{\prime}(x)$, $p(x)>0, q(x) \geq 0$ adalah fungsi kontinu pada domain $\Omega=(0, L)$.

Dari persamaan (8) dapat dilihat bahwa penyelesaian $u$ adalah di dalam ruang Sobolev $\mathcal{H}^{2}(\Omega)$. Dengan menggunakan hasilkali dalam

$$
\langle u, v\rangle=\int_{\Omega} u(x) v(x) d x,
$$

diperoleh formulasi variasional

$$
\langle A u, v\rangle=\lambda\langle u, v\rangle \text { untuk semua } v \in H_{A}
$$

dengan $H_{A}$ adalah ruang fungsi admissible yang memuat $u$ dan $v$. Kemudian dapat diperoleh

$$
\begin{aligned}
\langle A u, v\rangle & =\int_{0}^{L}\left[-\frac{d}{d x}\left(p \frac{d u}{d x}\right)+q u\right] v d x \\
& =\int_{0}^{L}\left[p \frac{d u}{d x} \frac{d v}{d x}+q u v\right] v d x-\left[v\left(p \frac{d u}{d x}\right)\right]_{0}^{L}
\end{aligned}
$$

Dari persamaan (10) dapat dilihat bahwa ruang fungsi admissibel yang sesuai berada dalam ruang Sobolev $\mathcal{H}^{\prime}(\Omega)$. Carey dan Oden [1983] menambahkan bahwa fungsi trial dan fungsi tes harus memenuhi syarat batas essensial dari masalah yang diberikan, yaitu syarat batas yang memberikan nilai-nilai turunan dengan orde $0,1,2, \ldots, m-1$ dengan $m$ adalah derajat dari ruang fungsi admissibel, dalam hal ini adalah ruang Sobolev. Dengan demikian, berdasarkan syarat batas (2a) dan (2b) dapat diperoleh

$$
B(u, v)=\langle A u, v\rangle=\int_{0}^{L}\left[p \frac{d u}{d x} \frac{d v}{d x}+q u v\right] v d x
$$

sehingga (9) menjadi

$B(u, v)=\lambda\langle u, v\rangle$ untuk semua $v \in H_{A}$.

\section{Metode Elemen Hingga untuk Persamaan}

\section{Sturm-Liouville}

Dalam metode elemen hingga pertama dibentuk domain $\bar{\Omega}=\Omega \cup \Gamma$ dari $\Omega=(0, L)$ dengan $\Gamma$ adalah batas dari $\Omega$. Selanjutnya domain $\bar{\Omega}$ dibagi menjadi berhingga $E$ subdomain $\bar{\Omega}_{e}, e=1,2, \ldots, E$ sesuai dengan ketentuan sebelumnya. Untuk menerapkan interpolasi Hermite dibentuk elemen $\bar{\Omega}_{e}=\left[x_{1}^{e}, x_{2}^{e}\right]$. Panjang tiap elemen adalah $h_{e}=x_{2}{ }^{e}-x_{1}{ }^{e}$ dan berlaku $x_{2}{ }^{e}=x_{1}{ }^{e+1}$.

Langkah selanjutnya adalah dikonstruksikan fungsi bentuk $\psi_{i}^{e}, i=1,2, \ldots, N_{e}$ untuk tiaptiap elemen $\bar{\Omega}^{e}$ sehingga fungsi pendekatan $u^{h}$ dapat disajikan dengan

$$
u_{e}^{h}=\sum_{j=1}^{N_{e}} \alpha_{j}^{e} \psi_{j}^{e}, \quad e=1,2, \ldots, E .
$$


Dengan menggunakan interpolasi Hermite kubik dapat diperoleh penyelesaian pendekatan untuk tiap elemen $\bar{\Omega}^{e}$, yaitu

$$
u_{h}^{e}(x)=\sum_{j=1}^{2} u_{j}^{e} \psi_{j}^{0^{e}}(x)+\frac{h_{e}}{2} \sum_{j=1}^{2} u_{j}^{e^{\prime}} \psi_{j}^{1^{e}}(x)
$$

dengan fungsi-fungsi bentuk pada elemen $\bar{\Omega}^{e}$ adalah

$$
\begin{aligned}
& \psi_{1}^{0^{e}}(x)=\left[\left(x-x_{2}^{e}\right)^{2}\left(2\left(x-x_{1}^{e}\right)+h_{e}\right)\right] / h_{e}^{3}, \\
& \psi_{1}^{1^{e}}(x)=\left[2\left(x-x_{2}^{e}\right)^{2}\left(x-x_{1}^{e}\right)\right] / h_{e}{ }^{3}, \\
& \psi_{2}^{0^{e}}(\xi)=\left[\left(x-x_{1}^{e}\right)^{2}\left(-2\left(x-x_{2}^{e}\right)+h_{e}\right)\right] / h_{e}{ }^{3}, \\
& \psi_{2}^{1^{e}}(\xi)=\left[2\left(x-x_{1}^{e}\right)^{2}\left(x-x_{2}^{e}\right)\right] / h_{e}{ }^{3} .
\end{aligned}
$$

Karena $x_{2}^{e}=x_{1}^{e+1}$ maka $u_{2}^{e}=u_{1}^{e+1}$ dan $(d u / d x)_{2}{ }^{e}=(d u / d x)_{1}{ }^{e+1}$. Hubungan ini digunakan dalam perakitan sistem dari seluruh sistem persamaan linear yang diperoleh dari tiap elemen.

Jika digunakan formulasi variasional (9) dalam elemen $\bar{\Omega}^{e}$ maka diperoleh

$\int_{x_{1}^{e}}^{x_{2}^{e}}\left[p_{e} \frac{d u}{d x} \frac{d v}{d x}+q_{e} u v\right] d x-\lambda \int_{x_{1}^{e}}^{x_{2}^{e}} u v d x-Q_{1}^{e} v\left(x_{1}^{e}\right)-Q_{2}^{e} v\left(x_{2}^{e}\right)=0$,

dengan $Q_{1}^{e}=\left.\left(p_{e} u^{\prime}\right)\right|_{x_{1}^{e}}$ dan $Q_{2}^{e}=\left.\left(-p_{e} u^{\prime}\right)\right|_{x_{2}^{e}}$.

Dengan menggunakan polinomial Hermite (12), diperoleh penyelesaian pendekatan

$$
\begin{aligned}
u_{h}^{e}(x) & =\sum_{j=1}^{2} u_{j}^{e} \psi_{j}^{0^{e}}(x)+\frac{h_{e}}{2} \sum_{j=1}^{2} u_{j}^{e^{\prime}} \psi_{j}^{1^{e}}(x) \\
& =\sum_{j=1}^{4} \alpha_{j}^{e} \psi_{j}^{e}(x)
\end{aligned}
$$

dengan $\quad \alpha_{1}^{e}=u_{1}^{e}, \quad \alpha_{2}^{e}=\frac{h_{e}}{2} u_{1}^{\prime}{ }^{e}, \quad \alpha_{3}^{e}=u_{2}^{e}$, $\alpha_{4}^{e}=\frac{h_{e}}{2} u_{2}^{e^{e}}, \psi_{1}^{e}=\psi_{1}^{0^{e}}, \psi_{2}^{e}=\psi_{1}^{1^{e}} \psi_{3}^{e}=\psi_{2}^{0^{e}}$, dan $\psi_{4}^{e}=\psi_{2}^{1^{e}}$. Subtitusi (15) ke dalam (14) dan dipilih $v=\psi_{i}^{e}, i=1,2,3,4$ diperoleh

$$
\sum_{j=1}^{N} \alpha_{j}{ }^{e}{k_{i j}}^{e}-\lambda \sum_{j=1}^{N} \alpha_{j}{ }^{e} m_{i j}{ }^{e}-r_{i}{ }^{e}=0
$$

dengan

$$
k_{i j}^{e}=\int_{x_{1}^{e}}^{x_{2}^{e}}\left[p_{e}\left(\psi_{i}^{e}\right)^{\prime}\left(\psi_{j}^{e}\right)^{\prime}+q_{e} \psi_{i}^{e} \psi_{j}^{e}\right] d x,
$$

$m_{i j}^{e}=\int_{x_{1}^{e}}^{x_{2}^{e}} \psi_{i}^{e} \psi_{j}^{e} d x$, dan

$r_{i}^{e}=Q_{1} \psi_{i}^{e}\left(x_{1}^{e}\right)+Q_{2} \psi_{i}^{e}\left(x_{2}^{e}\right)$.

Untuk selanjutnya dapat disajikan sebagai persamaan matriks

$$
\mathbf{K}^{e} \mathbf{u}^{e}=\lambda \mathbf{M}^{e} \mathbf{u}^{e}+\mathbf{r}^{e}
$$

dengan $\quad \mathbf{K}^{e}=\left[k_{i j}{ }^{e}\right], \quad \mathbf{M}^{e}=\left[m_{i j}{ }^{e}\right], \quad \mathbf{r}^{e}=\left[r_{i}{ }^{e}\right], \quad$ dan $\mathbf{u}^{e}=\left[\alpha_{j}^{e}\right]$. Persamaan (17) dapat disajikan dalam bentuk $\mathbf{G}^{e} \quad \mathbf{u}^{e}=\mathbf{r}^{e}$ dengan entri-entri $g_{i j}{ }^{\mathrm{e}}=k_{i j}{ }^{e}-\lambda m_{i j}{ }^{e}$. Untuk elemen ke- $E$ dapat diperoleh persamaan matriks

$$
\left[\begin{array}{llll}
g_{11}^{E} & g_{12}^{E} & g_{13}^{E} & g_{14}^{E} \\
g_{21}^{E} & g_{22}^{E} & g_{23}^{E} & g_{24}^{E} \\
g_{31}^{E} & g_{32}^{E} & g_{33}^{E} & g_{34}^{E} \\
g_{41}^{E} & g_{42}^{E} & g_{43}^{E} & g_{44}^{E}
\end{array}\right]\left[\begin{array}{c}
\alpha_{1}^{E} \\
\alpha_{2}^{E} \\
\alpha_{3}^{E} \\
\alpha_{4}^{E}
\end{array}\right]=\left[\begin{array}{c}
Q_{1}^{E} \\
0 \\
Q_{2}^{E} \\
0
\end{array}\right] .
$$

Dari pembagian domain diperoleh hubungan antar elemen $u_{2}^{e}=u_{1}^{e+1}$ dan $u_{2}^{e}=u_{1}^{e+1}$ sehingga berlaku $\alpha_{3}^{e}=\alpha_{1}^{e+1}$ dan $\alpha_{4}^{e}=\alpha_{2}^{e+1}$. Dengan demikian dapat dinyatakan $\alpha_{1}^{1}=U_{1}, \alpha_{2}^{1}=U_{2}$, $\alpha_{3}^{1}=U_{3}=\alpha_{1}^{2}, \quad \alpha_{4}^{1}=U_{4}=\alpha_{2}^{2}, \quad \alpha_{3}^{2}=U_{5}=\alpha_{1}^{3}$, $\ldots, \quad \alpha_{3}^{E-1}=U_{2 E-1}=\alpha_{1}^{E}, \quad \alpha_{4}^{E-1}=U_{2 E}=\alpha_{2}^{E}$, $\alpha_{3}^{E}=U_{2 E+1}, \quad \alpha_{4}^{E}=U_{2 E+2} \quad$ sehingga diperoleh hasil perakitan semua persamaan tiap elemen yang disajikan dalam bentuk persamaan matriks

$\mathbf{G U}=\mathbf{r}$, 
dengan matriks $\mathbf{G}$, vektor $\mathbf{U}$ dan $\mathbf{r}$ seperti

pada persamaan 18 .

Selanjutnya karena $x_{2}^{e}=x_{1}^{e+1}$, maka $Q_{2}^{e}+Q_{1}^{e+1}=0, e=1,2, \ldots, E \quad$ sehingga diperoleh

$\mathbf{r}=\left[\begin{array}{lllllllllll}Q_{1} & 0 & 0 & 0 & 0 & 0 & \cdots & 0 & 0 & Q_{2}^{E} & 0\end{array}\right]$.

Penerapan syarat batas (2a ) dan (2b) adalah sebagai berikut berikut
2. Syarat batas Campuran

a) Penerapan syarat batas campuran $u(0)=0 \quad$ dan $\quad u^{\prime}(L)=0 \quad$ menghasilkan persamaan matriks (20).

b) Penerapan syarat batas campuran $u^{\prime}(0)=0 \quad$ dan $\quad u(L)=0 \quad$ menghasikan persaamaan matriks (21).

Untuk mendapatkan $\mathbf{U} \neq 0$ harus dicari $\lambda$ sehingga det $(\mathbf{K}-\lambda \mathbf{M})=0$. Akar-akar dari persamaan $(\mathbf{K}-\lambda \mathbf{M})=0$ adalah nilai-nilai eigen

$$
\begin{aligned}
& G=\left[\begin{array}{ccccccccccc}
g_{11}^{1} & g_{12}^{1} & g_{13}^{1} & g_{14}^{1} & 0 & 0 & \cdots & 0 & 0 & 0 & 0 \\
g_{21}^{1} & g_{22}^{1} & g_{23}^{1} & g_{24}^{1} & 0 & 0 & \cdots & 0 & 0 & 0 & 0 \\
g_{31}^{1} & g_{32}^{1} & g_{33}^{1}+g_{11}^{2} & g_{34}^{1}+g_{12}^{2} & g_{13}^{2} & g_{14}^{2} & \cdots & 0 & 0 & 0 & 0 \\
g_{41}^{1} & g_{41}^{1} & g_{43}^{1}+g_{21}^{2} & g_{44}^{1}+g_{22}^{2} & g_{23}^{2} & g_{24}^{2} & \cdots & 0 & 0 & 0 & 0 \\
0 & 0 & g_{31}^{2} & g_{32}^{2} & g_{33}^{2}+g_{11}^{3} & g_{34}^{2}+g_{12}^{3} & \cdots & 0 & 0 & 0 & 0 \\
0 & 0 & g_{41}^{2} & g_{42}^{2} & g_{43}^{2}+g_{21}^{3} & g_{44}^{2}+g_{22}^{3} & \cdots & 0 & 0 & 0 & 0 \\
\vdots & \vdots & \vdots & \vdots & \vdots & \vdots & \cdots & \vdots & \vdots & \vdots & \vdots \\
0 & 0 & 0 & 0 & 0 & 0 & \cdots & g_{33}^{E-1}+g_{11}^{E} & g_{34}^{E-1}+g_{12}^{E} & g_{13}^{E} & g_{14}^{E} \\
0 & 0 & 0 & 0 & 0 & 0 & \cdots & g_{43}^{E-1}+g_{21}^{E} & g_{44}^{E-1}+g_{22}^{E} & g_{23}^{E} & g_{24}^{E} \\
0 & 0 & 0 & 0 & 0 & 0 & \cdots & g_{31}^{E} & g_{32}^{E} & g_{33}^{E} & g_{34}^{E} \\
0 & 0 & 0 & 0 & 0 & 0 & \cdots & g_{41}^{E} & g_{42}^{E} & g_{43}^{E} & g_{44}^{E}
\end{array}\right], \\
& \mathbf{U}=\left[\begin{array}{lllllllllllll}
U_{1} & U_{2} & U_{3} & U_{4} & U_{5} & U_{6} & \cdots & U_{2 E-1} & U_{2 E} & U_{2 E+1} & U_{2+2}
\end{array}\right]^{T}, \text { dan }
\end{aligned}
$$

$$
\left[\begin{array}{ccc}
g_{22}^{1} & g_{23}^{1} & g_{24}^{1} \\
g_{32}^{1} & g_{33}^{1}+g_{11}^{2} & g_{34}^{1}+g_{12}^{2} \\
g_{42}^{1} & g_{43}^{1}+g_{21}^{2} & g_{44}^{1}+g_{22}^{2} \\
0 & g_{31}^{2} & g_{32}^{2} \\
0 & g_{41}^{2} & g_{42}^{2} \\
\vdots & \vdots & \vdots \\
0 & 0 & 0 \\
0 & 0 & 0 \\
0 & 0 & 0
\end{array}\right.
$$

$$
\begin{array}{cc}
0 & 0 \\
g_{13}^{2} & g_{14}^{2} \\
g_{23}^{2} & g_{24}^{2} \\
g_{33}^{2}+g_{11}^{3} & g_{34}^{2}+g_{12}^{3} \\
g_{43}^{2}+g_{21}^{3} & g_{44}^{2}+g_{22}^{3} \\
\vdots & \vdots \\
0 & 0 \\
0 & 0 \\
0 & 0
\end{array}
$$$$
\begin{array}{ccc}
\cdots & 0 & 0 \\
\cdots & 0 & 0 \\
\cdots & 0 & 0 \\
\cdots & 0 & 0 \\
\cdots & 0 & 0 \\
\cdots & \vdots & \vdots \\
\cdots & g_{33}^{E-1}+g_{11}^{E} & g_{34}^{E-1}+g_{12}^{E} \\
\cdots & g_{43}^{E-1}+g_{21}^{E} & g_{44}^{E-1}+g_{22}^{E} \\
\cdots & g_{41}^{E} & g_{42}^{E}
\end{array}
$$$$
\left.\begin{array}{c}
0 \\
0 \\
0 \\
0 \\
0 \\
\vdots \\
g_{14}^{E} \\
g_{24}^{E} \\
g_{44}^{E}
\end{array}\right]\left[\begin{array}{c}
U_{2} \\
U_{3} \\
U_{4} \\
U_{5} \\
U_{6} \\
\vdots \\
U_{2 E-1} \\
U_{2 E} \\
U_{2 E+2}
\end{array}\right]=\left[\begin{array}{l}
0 \\
0 \\
0 \\
0 \\
0 \\
\vdots \\
0 \\
0 \\
0
\end{array}\right] .
$$

1. Syarat batas Dirichlet

Penerapan syarat batas Dirichlet adalah $u(0)=0$ dan $u(L)=0$ menghasilkan persamaan matriks (19). pendekatan dan penyelesaian $\mathbf{U}$ yang terkait adalah dengan nilai eigen tersebut digunakan untuk memperoleh fungsi eigen pendekatan pada persamaan (15). 
$-\left[\begin{array}{ccccccccc}g_{22}^{1} & g_{23}^{1} & g_{24}^{1} & 0 & 0 & \cdots & 0 & 0 & 0 \\ g_{32}^{1} & g_{33}^{1}+g_{11}^{2} & g_{34}^{1}+g_{12}^{2} & g_{13}^{2} & g_{14}^{2} & \cdots & 0 & 0 & 0 \\ g_{42}^{1} & g_{43}^{1}+g_{21}^{2} & g_{44}^{1}+g_{22}^{2} & g_{23}^{2} & g_{24}^{2} & \cdots & 0 & 0 & 0 \\ 0 & g_{31}^{2} & g_{32}^{2} & g_{33}^{2}+g_{11}^{3} & g_{34}^{2}+g_{12}^{3} & \cdots & 0 & 0 & 0 \\ 0 & g_{41}^{2} & g_{42}^{2} & g_{43}^{2}+g_{21}^{3} & g_{44}^{2}+g_{22}^{3} & \cdots & 0 & 0 & 0 \\ \vdots & \vdots & \vdots & \vdots & \vdots & \cdots & \vdots & \vdots & 0 \\ 0 & 0 & 0 & 0 & 0 & \cdots & g_{33}^{E-1}+g_{11}^{E} & g_{34}^{E-1}+g_{12}^{E} & g_{13}^{E} \\ 0 & 0 & 0 & 0 & 0 & \cdots & g_{43}^{E-1}+g_{21}^{E} & g_{44}^{E-1}+g_{22}^{E} & g_{23}^{E} \\ 0 & 0 & 0 & 0 & 0 & \cdots & g_{31}^{E} & g_{32}^{E} & g_{33}^{E}\end{array}\right]\left[\begin{array}{c}U_{2} \\ U_{3} \\ U_{4} \\ U_{5} \\ U_{6} \\ \vdots \\ U_{2 E-1} \\ U_{2 E} \\ U_{2 E+1}\end{array}\right]=\left[\begin{array}{c}0 \\ 0 \\ 0 \\ 0 \\ 0 \\ \vdots \\ 0 \\ 0 \\ 0\end{array}\right]$

$\left[\begin{array}{ccccccccc}g_{11}^{1} & g_{13}^{1} & g_{14}^{1} & 0 & 0 & \cdots & 0 & 0 & 0 \\ g_{31}^{1} & g_{33}^{1}+g_{11}^{2} & g_{34}^{1}+g_{12}^{2} & g_{13}^{2} & g_{14}^{2} & \cdots & 0 & 0 & 0 \\ g_{41}^{1} & g_{43}^{1}+g_{21}^{2} & g_{44}^{1}+g_{22}^{2} & g_{23}^{2} & g_{24}^{2} & \cdots & 0 & 0 & 0 \\ 0 & g_{31}^{2} & g_{32}^{2} & g_{33}^{2}+g_{11}^{3} & g_{34}^{2}+g_{12}^{3} & \cdots & 0 & 0 & 0 \\ 0 & g_{41}^{2} & g_{42}^{2} & g_{43}^{2}+g_{21}^{3} & g_{44}^{2}+g_{22}^{3} & \cdots & 0 & 0 & 0 \\ \vdots & \vdots & \vdots & \vdots & \vdots & \cdots & \vdots & \vdots & \vdots \\ 0 & 0 & 0 & 0 & 0 & \cdots & g_{33}^{E-1}+g_{11}^{E} & g_{34}^{E-1}+g_{12}^{E} & g_{14}^{E} \\ 0 & 0 & 0 & 0 & 0 & \cdots & g_{43}^{E-1}+g_{21}^{E} & g_{44}^{E-1}+g_{22}^{E} & g_{24}^{E} \\ 0 & 0 & 0 & 0 & 0 & \cdots & g_{41}^{E} & g_{42}^{E} & g_{44}^{E}\end{array}\right]\left[\begin{array}{c}U_{1} \\ U_{3} \\ U_{4} \\ U_{5} \\ U_{6} \\ \vdots \\ U_{2 E-1} \\ U_{2 E} \\ U_{2 E+2}\end{array}\right]=\left[\begin{array}{c}0 \\ 0 \\ 0 \\ 0 \\ 0 \\ \vdots \\ 0 \\ 0 \\ 0\end{array}\right]$.

Dari langkah-langkah yang telah diberikan di atas maka metode ini dapat digunakan untuk menyelesaikan contoh berikut.

\section{Contoh 1:}

Perhatikan persamaan Sturm-Liouville

$-\frac{d^{2} u}{d x^{2}}+2 u=\lambda u, \quad 0<x<\pi$

dengan syarat batas campuran $u(0)=u^{\prime}(\pi)=0$.

Penyelesaian eksak dari persamaan (22) adalah $\lambda_{i}=(i-0.5)^{2}+2$ dan

$$
u_{i}(x)=c \sqrt{\frac{\pi}{2}} \operatorname{Sin}\left(\left(i-\frac{1}{2}\right) x\right)
$$

dengan $c$ konstanta dan $i=1,2,3, \ldots$

Untuk menyelesaikan masalah (22) dengan menggunakan elemen hingga Hermite kubik, terlebih dahulu domain $\bar{\Omega}$ dibagi menjadi berhingga banyak elemen, misalkan $E$. Dapat ditentukan misalkan elemen ke-e adalah $\bar{\Omega}^{e}=[h(e-1), h e]$ dengan $h=h_{e}=\pi / 2$ untuk $e=1,2, . ., E$.

Selanjutnya dapat ditentukan fungsi eigen pendekatan untuk tiap-tiap elemen seperti dalam persamaan (15). Misalkan ditentukan banyaknya elemen adalah 2, maka diperoleh elemen

$\bar{\Omega}^{1}=[0, \pi / 2]$ dan $\bar{\Omega}^{2}=[\pi / 2, \pi]$ dan $h=\pi / 2$.

Dengan menerapkan (17) dan syarat batasnya, diperoleh persamaan

$\left[\begin{array}{cccc}0.459-0.059 \lambda & 0.067-0.097 \lambda & -0.174+0.044 \lambda & 0 \\ 0.067-0.097 \lambda & 3.861-1.166 \lambda & 0 & -0.360-0.201 \lambda \\ -0.174+0.044 \lambda & 0 & 0.918-0.119 \lambda & 0.067-0.097 \lambda \\ 0 & -0.360-0.201 \lambda & 0.067-0.097 \lambda & 1.930-0.583 \lambda\end{array}\right]\left[\begin{array}{l}U_{2} \\ U_{3} \\ U_{4} \\ U_{5}\end{array}\right]=\left[\begin{array}{l}0 \\ 0 \\ 0 \\ 0\end{array}\right]$.

Untuk mendapatkan penyelesaian nontrivial, maka dicari nilai $\lambda$ yang memenuhi

$\operatorname{det}\left(\left[\begin{array}{cccc}0.459-0.059 \lambda & 0.067-0.097 \lambda & -0.174+0.044 \lambda & 0 \\ 0.067-0.097 \lambda & 3.861-1.166 \lambda & 0 & -0.360-0.201 \lambda \\ -0.174+0.044 \lambda & 0 & 0.918-0.119 \lambda & 0.067-0.097 \lambda \\ 0 & -0.360-0.201 \lambda & 0.067-0.097 \lambda & 1.930-0.583 \lambda\end{array}\right]\right)=0$

Dari persamaan (23) diperoleh nilai-nilai eigen pendekatan $\lambda_{1}^{h}=2.25, \quad \lambda_{2}^{h}=4.25417, \quad \lambda_{3}^{h}=$ 8.38806, $\lambda_{4}^{h}=15.8836$ dan fungsi-fungsi eigen pendekatan 
$u_{1}^{h}(x)=\left\{\begin{array}{l}c\left(0.5010 x-0.0037 x^{2}-0.0182 x^{3}\right), \\ c\left(-0.0543+0.5966 x-0.0593 x^{2}-0.0075 x^{3}\right),\end{array}\right.$
$u_{2}^{h}(x)=\left\{\begin{array}{l}c\left(-1.615 x+0.469 x^{2}+0.173 x^{3}\right), \\ c\left(0.651-3.903 x+2.590 x^{2}-0.417 x^{3}\right),\end{array}\right.$
$u_{3}^{h}(x)=\left\{\begin{array}{l}c\left(3.634 x-3.850 x^{2}+0.796 x^{3}\right), \\ c\left(23.974-33.599 x+14.406 x^{2}-1.922 x^{3}\right),\end{array}\right.$

$0<x \leq \frac{\pi}{2}$
$\frac{\pi}{2}<x \leq \pi$

$0<x \leq \frac{\pi}{2}$

$\frac{\pi}{2}<x \leq \pi$,

$0<x \leq \frac{\pi}{2}$

$\frac{\pi}{2}<x \leq \pi$,

$u_{4}^{h}(x)= \begin{cases}c\left(-12.016 x+21.568 x^{2}-8.678 x^{3}\right), & 0<x \leq \frac{\pi}{2} \\ c\left(55.5594-70.213 x+28.115 x^{2}-3.594 x^{3}\right), & \frac{\pi}{2}<x \leq \pi,\end{cases}$

untuk $c$ suatu konstanta.

Hasil penghitungan nilai eigen pendekatan dengan elemen hingga Hermite kubik untuk nilai $E=2,4$, dan 8 tampak pada Tabel 1. Dari Tabel 1, dapat dilihat bahwa error nilai eigen pendekatan akan semakin bagus jika jumlah elemen semakin banyak (panjang elemennya semakin kecil). Akan tetapi, error semakin besar seiring dengan semakin besarnya indeks nilai eigen. Hal ini juga berlaku pada fungsi eigen pendekatan.

Tabel 1. Nilai eigen pendekatan dari contoh soal yang telah dihitung dengan Mathematica untuk jumlah elemen $E=2,4,8$, dan 16

\begin{tabular}{|c|c|c|l|l|}
\hline Eigen & $E=2$ & $E=4$ & $E=8$ & Eksak \\
\hline$\lambda_{1}$ & 2.25 & 2.25 & 2.25 & 2.25 \\
\hline$\lambda_{2}$ & 4.25417 & 4.25013 & 4.25 & 4.25 \\
\hline$\lambda_{3}$ & 8.38806 & 8.25488 & 8.25014 & 8.25 \\
\hline$\lambda_{4}$ & 15.8836 & 14.2965 & 14.2516 & 14.25 \\
\hline$\lambda_{5}$ & - & 22.5112 & 22.2595 & 22.25 \\
\hline$\lambda_{6}$ & - & 33.3742 & 32.2873 & 32.25 \\
\hline$\lambda_{7}$ & - & 48.287 & 44.3638 & 44.25 \\
\hline$\lambda_{8}$ & - & 66.2227 & 58.5422 & 58.25 \\
\hline
\end{tabular}

Jika error fungsi eigen dihitung dengan

menggunakan norm kuadrat rata-rata berikut,

$$
\left\|\bar{u}_{i}-\bar{u}_{i}^{h}\right\|_{0}=\left\{\int_{0}^{L}\left|\bar{u}_{i}-\bar{u}_{i}^{h}\right|^{2} d x\right\}^{\frac{1}{2}}
$$

dengan $\bar{u}_{i}$, dan $\bar{u}_{i}^{h}$ adalah fungsi eigen eksak dan pendekatan yang telah dinormalkan, maka diperoleh error seperti pada Tabel 2.

Tabel 2. Error fungsi eigen pendekatan dari contoh soal yang telah dihitung dengan Mathematica untuk jumlah elemen $E=2,4$, dan 8 .

\begin{tabular}{|c|c|c|c|}
\hline \multirow{2}{*}{$\begin{array}{c}\text { Fungsi } \\
\text { Eigen }\end{array}$} & \multicolumn{3}{|c|}{$\left\|\bar{u}_{i}-\bar{u}_{i}^{h}\right\|_{0}$} \\
\cline { 2 - 4 } & $E=2$ & $E=4$ & $E=8$ \\
\hline$u_{1}$ & $2.9611 \times 10^{-4}$ & $2.0733 \times 10^{-5}$ & $1.3373 \times 10^{-6}$ \\
\hline$u_{2}$ & 0.0125014 & $1.2807 \times 10^{-3}$ & $9.9900 \times 10^{-5}$ \\
\hline$u_{3}$ & 0.0630196 & $6.9964 \times 10^{-3}$ & $6.7065 \times 10^{-4}$ \\
\hline$u_{4}$ & 0.3646037 & 0.0215540 & $2.1762 \times 10^{-3}$ \\
\hline$u_{5}$ & - & 0.0436230 & $4.9927 \times 10^{-3}$ \\
\hline$u_{6}$ & - & 0.0955514 & $9.4676 \times 10^{-3}$ \\
\hline$u_{7}$ & - & 0.0215540 & 0.0163075 \\
\hline$u_{8}$ & - & 0.0436230 & 0.0323568 \\
\hline
\end{tabular}

Dari Tabel 2, dapat dilihat bahwa fungsi eigen pendekatan yang dihasilkan cukup baik. Seperti halnya pada nilai eigen pendekatan, norm error ini akan semakin kecil jika jumlah elemennya semakin bertambah, tapi error semakin besar seiring dengan besarnya indeks dari fungsi eigennya. Hasil yang kurang lebih sama dapat dilihat pada contoh berikut.

Contoh 2:

Perhatikan persamaan Sturm-Liouville $-\frac{d^{2} u}{d x^{2}}=\lambda u, \quad 0<x<1$

dengan syarat batas Dirichlet $u(0)=u(1)=0$. Nilai eigen eksak dari persamaan (4.17) adalah 
$\lambda_{i}=i^{2} \pi^{2}$ dan fungsi eigen eksaknya adalah $u_{i}(x)=c \operatorname{Sin}(i \pi x)$.

Dengan metode yang sama diperoleh hasil nilai eigen dan fungsi eigen pendekatan seperti pada Tabel 3 dan Tabel 4.

Tabel 3 Nilai eigen pendekatan untuk Contoh 2 menggunakan elemen hingga Hermite kubik dengan $E=$ $2,4,8,16$

\begin{tabular}{|c|c|c|c|c|}
\hline Eigen & $E=2$ & $E=4$ & $E=8$ & Eksak \\
\hline$\lambda_{1}$ & 9.87218 & 9.86967 & 9.86961 & 9.8696 \\
\hline$\lambda_{2}$ & 40.0 & 39.4887 & 39.4787 & 39.4784 \\
\hline$\lambda_{3}$ & 94.2509 & 88.9912 & 88.8317 & 88.8264 \\
\hline$\lambda_{4}$ & 168.0 & 160.0 & 157.955 & 157.914 \\
\hline$\lambda_{5}$ & - & 252.19 & 246.933 & 246.74 \\
\hline$\lambda_{6}$ & - & 377.004 & 355.965 & 355.306 \\
\hline$\lambda_{7}$ & - & 548.143 & 485.466 & 483.611 \\
\hline$\lambda_{8}$ & - & 672.0 & 640.0 & 631.655 \\
\hline
\end{tabular}

Tabel 4 Error fungsi eigen pendekatan untuk

Contoh 2 menggunakan elemenhingga Hermite kubik dengan $E=2,4,8$.

\begin{tabular}{|l|c|c|c|}
\hline \multicolumn{1}{|c|}{ Error } & $E=2$ & $E=4$ & $E=8$ \\
\hline$\left\|\bar{u}_{1}-\bar{u}_{1}{ }^{h}\right\|$ & 0.0034002 & 0.0002961 & 0.0000207 \\
\hline$\left\|\bar{u}_{2}-\bar{u}_{2}{ }^{h}\right\|$ & 0.0380198 & 0.0034002 & 0.0002961 \\
\hline$\left\|\bar{u}_{3}-\bar{u}^{h}\right\|$ & 0.1483822 & 0.0125014 & 0.0012807 \\
\hline$\left\|\bar{u}_{4}-\bar{u}_{4}{ }^{h}\right\|$ & 0.1308460 & 0.0380198 & 0.0034002 \\
\hline$\left\|\bar{u}_{5}-\bar{u}_{5}{ }^{h}\right\|$ & - & 0.0630196 & 0.0069963 \\
\hline$\left\|\bar{u}_{6}-\bar{u}_{6}{ }^{h}\right\|$ & - & 0.1483822 & 0.0125014 \\
\hline$\left\|\bar{u}_{7}-\bar{u}_{7}{ }^{h}\right\|$ & - & 0.3646037 & 0.0215540 \\
\hline$\left\|\bar{u}_{8}-\bar{u}_{8}{ }^{h}\right\|$ & - & $\begin{array}{l}0 . \\
1308460\end{array}$ & 0.0323009 \\
\hline
\end{tabular}

Sebagaimana pada Contoh 1, error baik nilai eigen dan fungsi eigen pendekatan cukup baik, di mana keduanya sangat dipengaruhi oleh panjang elemen yang digunakan dan indek nilai atau fungsi eigen yang dihitung. Namun demikian karena beberapa keterbatasan, pembahasan secara detail mengenai perilaku error nilai eigen dan fungsi eigen pendekatan akan dijadikan topik untuk penulisan makalah berikutnya.

\section{PENUTUP}

Dari hasil di atas disimpulkan bahwa metode elemen hingga Hermite kubik dapat diterapkan dengan baik untuk menyelesaikan persamaan Sturm-Liouville berorde dua. Langkah-langkah penyelesaiannya adalah sebagai berikut.

1. Membagi domain menjadi elemenelemen

2. Memilih interpolasi untuk masingmasing elemen, dalam penelitian ini digunakan interpolasi Hermite kubik.

3. Menerapkan formulasi variasional untuk tiap-tiap elemen sehingga diperoleh persamaan linear untuk tiap-tiap elemen.

4. Melakukan perakitan terhadap persamaan linear dari tiap-tiap elemen.

5. Menerapkan syarat batas.

6. Menghitung nilai eigen dan fungsi eigen dari persamaan linear akhir. 


\section{DAFTAR PUSTAKA}

Carey, G. F., and J. T. Oden, 1983. Finite Element: A Second Course Volume II. New Jersey: Prentice Hall, Inc.

Gerald, C. F., and P. O. Wheatley, 1994. Applied Numerical Analysis. AddisonWesley Publicing Company, Inc.

Griffin, T. B. and B. D. Reddy, 1988. Variational Principles and Convergence of Finite Element Aproximation of a Holonomic ElasticPlastic Problem. Numerische Mathematik Volume 52: 101-117. Springer-Verlag

Reddy, J. N., 1984. An Introduction to the Finite Element Method. New York: McGraw Hill, Inc.

Reddy, J. N., 1986. Applied Functional Analysis and Variational Methods in Engeneering. New York: McGraw Hill, Inc.

Strang, G., and G. Fix, 1973. An Analysis of Finite Element Method. New Jersey: Prentice Hall, Inc. 